\title{
How and why do nectar-foraging bumblebees initiate movements between inflorescences of wild bergamot Monarda fistulosa (Lamiaceae)?
}

\author{
James E. Cresswell \\ Department of Biology, University of Michigan, Ann Arbor, MI 48109, USA \\ Received June 22, 1989 / Accepted November 13, 1989
}

\begin{abstract}
Summary. By experimental manipulation of the nectar in flowers, I characterized the decision-making process used by nectar-gathering bumblebees for initiating movements between inflorescences of wild bergamot. The decision-making process has these characteristics: departure from an inflorescence is less likely as nectar rewards increase; departure decisions are based on the amount of nectar in the last flower probed and are not influenced by the nectar rewards in either the previously probed flower or the previously visited inflorescence; the number of flowers already probed at an inflorescence influences departure decisions weakly; a bees' response (to stay or to depart) to a given size of nectar reward is variable. Since previously proposed foraging rules do not accord with this description, I propose a new rule. I show by experiment that the movements made by bumblebees enhance foraging success.
\end{abstract}

Key words: Bumblebees -- Bergamot - Foraging - Nectar - Optimal foraging theory

In this paper, I address 5 related subjects. First, I suggest that realistic characterization of decision-making processes are essential for the most fruitful optimal foraging models. Second, I describe the behavior of nectar-gathering bumblebees foraging among inflorescences of wild bergamot and, by experiment, show that the frequent movements made by bees between inflorescences enhance foraging success. Third, by experimental manipulation of nectar rewards, I attempt to characterize the decision-making process governing the movements of the bumblebees that I studied. Fourth, I use data from the experiments to test for the applicability of some previously proposed decision-making rules to the bees. Since the pre-existing rules do not describe the observed behavior well, I propose a novel model. Finally, I suggest that an understanding of bumblebees' response to the nectar rewards that they encounter will direct speculation about the adaptiveness of nectar production strategies exhibited by plants pollinated by bumblebees. In particular, I use data from my experiments to address the possible effect of variability in nectar rewards on the pollination success of the plants.

\section{The value of realism in optimal foraging models}

Presumably, animals have undergone natural selection for the adoption of foraging behaviors that maximize gain in a currency that ultimately translates into fitness (Schoener 1971). Often, it is assumed that the currency that is maximized is the net rate of energy intake (Emlen 1966; Schoener 1971; Stephens and Krebs 1986). What foraging behavior should the animal adopt to maximize its currency gain? Decision problems such as this have been addressed in models derived from optimal foraging theory. I suggest that a fruitful optimality analysis results from models that include a realistic characterization of the decision-making process of the animal as it operates in the wild because then the interaction between natural selection and behavior can be elucidated.

Optimality analysis of a model of foraging behavior leads to identification of the particular variant of a foraging strategy that gives the maximum possible rate of energy intake. Comparison of the success of the strategy adopted by the animal with that identified by the model can be used to determine whether there is the potential for selection for improved foraging behavior to operate. If, in the model, the forager is given perfect information for decision making [perfect sensory and cognitive abilities, i.e. a 'literal optimality' model (Mazur 1983)] then a difference between the rate of energy uptake of the animal and the model can indicate the potential for selection to improve sensory and cognitive capabilities of the animal because the difference indicates how much the foraging success (hence fitness) of the animal would be enhanced by improved capabilities. Similarly, if, in the 
model, the forager is given realistic information for decision making [realistic sensory and cognitive abilities, i.e. a 'constrained optimality' model (Maynard Smith 1978; Staddon and Hinson 1983)] then a difference between the rate of energy intake between the animal and the model indicates the potential for selection to improve the use of the present sensory and cognitive abilities of the animal. If the potential for selection is indicated as a result of optimality analyses, then it raises the question of why selection has not acted previously to improve foraging performance. Possible answers include the opposition of selection for improved foraging by other pressures through trade-offs, or the failure of the assumption that more food equals higher fitness. Therefore, much can be inferred about the likely action of selection on behavior and its interaction with other aspects of an animal's life history through including in foraging models both idealized and realistic characterizations of an animal's sensory and cognitive capabilities and the decision process that it uses.

Despite the importance to optimality analyses of discovering realistic decision-making mechanisms, it has been recognized repeatedly that little work has been directed towards identifying them (Ollason 1980; McNair 1985). Typically, investigations involving the construction of models of foraging behavior have emphasized testing the hypothesis that the animal attains literal optimality (e.g. Lima 1984, 1985). However, discrepancies between the performance of the animal and model may be because of the innaccuracy of the model and not be indicative of the potential for selection.

Some authors have recommended using comparisons with optimality models to infer the sensory and cognitive capabilities of animals (Cheverton et al. 1985). However, to the extent that one wishes to use optimality analyses to address evolutionary questions about the interaction between natural selection and foraging behavior, then it is important to derive the characterization of the animal independently from the formulation of a model, as is done here. [An optimality analysis of models of bumblebee foraging incorporating the findings of this paper is in Cresswell (1989)].

\section{Bumblebees as suitable experimental subjects}

Many animals forage for food items that are spatially distributed into discrete clumps or patches (MacArthur and Pianka 1966). Having begun to forage in a patch, an animal must decide how long to remain before moving to a new patch (Cowie 1977). Since the quality of patches varies, a prudent forager might make an assessment of the patch it is in, compare it with patches it has previously encountered, and decide whether it might be more profitable to move to a new patch. This type of problem has been addressed in optimal foraging models of patch departure (e.g. Charnov 1976; Cowie 1977). Bumblebees are well suited for optimality analyses of patch departure behavior because bumblebees often ex- ploit food items (nectar rewards in flowers) that are distributed in patches (inflorescences). Furthermore, models of foraging can be relatively simple since bumblebees' decisions may be focused entirely on net energy intake since foraging behavior is unlikely to be influenced by predation or searching for mates or nests, at least for the worker caste (Pyke 1979).

\section{What kinds of 'rules' might bumblebees use?}

Although useful qualitative investigations into inflorescence departure decisions by bumblebees have been made (Pyke 1982, 1979), only 1 potentially predictive, quantitative mechanism has been proposed; the 'threshold departure rule' for bumblebees foraging on Delphinium nelsonii (Hodges 1981, 1985a, b). The decision mechanism has a single parameter, the threshold; the bumblee leaves an inflorescence after receiving a subthreshold nectar reward. This rule can be efficient when the amounts of nectar in adjacent flowers are related, i.e. when a subthreshold reward is predictive of little nectar in the next flower also (Hodges 1985b). The rule was formulated to explain the behavior of bees foraging systematically on vertical inflorescences of 3 flowers. I test the generality of the rule for bumblebees in different circumstances since, on wild bergamot, bumblebees forage systematically on radially arranged inflorescences with usually 10-15 flowers. I also test the applicability of various models that were not intended specifically for bumblebees.

Contemporary mechanistic models are often formulated from the premise that animals make foraging decisions by a simple 'rule-of-thumb' (McNamara and Houston 1980; Janetos and Cole 1981). Decision making rules-of-thumb that have been investigated and that might be used in solution to the problem of when to move between inflorescences faced by bumblebees foraging on bergamot include giving-up-time rules where the forager leaves a patch after some interval without capturing a prey (Krebs et al. 1974; Iwasa et al. 1981) and counting rules where the forager leaves a patch after some number of trials and/or captures (Green 1980; Iwasa et al. 1981; Lima 1984, 1985). For the bumblebeebergamot system, fixed giving-up-time rules can be translated into fixed numbers of flowers searched without reward. The counting rule as stated by Green is inapplicable because it depends on the number of equally sized prey items captured in a patch, while the amount of nectar in flowers is a continuous variable. However, an analogous formulation might base movement decisions on the sum of the amount of nectar gathered at previous flowers.

\section{The role of nectar in pollination}

Bumblebees serve as pollinators for many plants. For these plants, reproductive success is, in part, determined by pollen flow that is mediated by bumblebees' move- 
ments. Bumblebee movements are directed towards harvesting nectar, and sometimes pollen also. Consequently, speculation about the adaptiveness for successful pollination of the nectar production strategy exhibited by plants can be informed by an understanding of how bumblebees respond to the nectar rewards that they encounter. In particular, there has been speculation about how nectar foragers might respond to variability in the nectar rewards that they encounter even when the mean reward is constant (Pleasants 1983; Zimmerman and Pyke 1986; Real and Rathcke 1988). In experiments involving the manipulation of nectar rewards, I test for an effect of variability in nectar rewards on bumblebee movements.

\section{Materials and methods}

\section{The system}

I studied a population of the wild bergamot, Monarda fistulosa (Lamiaceae) growing alongside a path through an old field at the E.S. George Biological Research Station, Livingston Co., MI. Flowering ramets grew up to $75 \mathrm{~cm}$ in height and bore 1-6 "capitulate' inflorescences. Flowers mature centrifugally on the capitula and dehisce on senescence so that a ring of open flowers is formed. The flowers are protandrous, sessile, tubular and about $15 \mathrm{~mm}$ long. Usually, there are 10-15 flowers open on an inflorescence.

The plants were foraged for nectar by 6 species of bumblebee, honeybees, solitary bees and sphinx moths. I studied workers of Bombus bimaculatus, which were the most numerous foragers. During the study periods, these bees were constant to $M$. fistulosa. Bees always flew between inflorescences and almost always walked between flowers on an inflorescence. As noted elsewhere (Cruden et al. 1984), bees foraged on the flowers systematically, usually by moving to the next unvisited flower in the ring and they did not appear to discriminate between the sexual phases of the flowers. While bees sometimes skipped a flower, rarely 2 flowers, during their progress around a ring, I did not observe bees passing over larger numbers of flowers. Bees almost always flew between neighbouring inflorescences, and long flights were rare. Bumblebees did not collect pollen, rather they would scrape off and discard any pollen with which they became dusted. Work was conducted between mid-July and early August 1986-1988.

\section{Describing behavior of free-flying bumblebees on unmanipulated inflorescences}

In 1987, on each of 9 days I followed at least 5 individual, freeflying bees as they visited approximately 20 consecutive inflorescences and recorded the number of flowers probed at each. To discover whether the bee integrates the nectar received from the previous inflorescence into its departure decisions, I used these data to test whether the number of flowers probed at an inflorescence was independent of the number probed at the previous inflorescence by composing $2 \times 2$ contingency tables with categories of $\leq 3$ and $>3$ probes at the nth versus the $(n+1)$ th inflorescence. I pooled the data that were collected from bees on a single day.

\section{Nectar measurements and manipulations}

I removed nectar from flowers by soaking it up into minute, pointed wicks cut from filter paper. This method of removing nectar and the subsequent assay of the sugars in them is detailed in McKenna and Thomson (1988). The residual amounts of nectar in flowers after probing with wicks or following a bee's visit were measured using the rinsing technique detailed in Cresswell (1989). Since both methods use an assay that compares the sample with a standard curve of sucrose solutions, nectar contents of flowers are estimated in units of $\mu \mathrm{g}$ sucrose equivalents ( $\mu \mathrm{gSEq})$. This is a good estimator for nectar since $M$. fistulosa nectar contains sucrose predominantly (I. Baker, personal communication). Also, the units are directly related to the energy value of the nectar reward.

In conducting the experiments described below, wicks were used for removing the nectar that was available to bees; after a visit to a flower by a bumblebee, an average of $69 \mu \mathrm{gSeq}(s=23$, $n=32$ ) was measured by rinsing whereas after wicking, only $33 \mu \mathrm{gSeq}(s=31, n=49)$ was measured. For a bumblebee, to encounter a recently wicked-out flower is to encounter an empty flower.

\section{Testing for the efficiency of bumblebees' movements between inflorescences}

After locating a free-flying bee, I dictated into a tape recorder a description of the bee's behavior over approximately 10 consecutively visited inflorescences to obtain estimates to flight and flower probing times. Then, I waited until the bee left an inflorescence after probing only 2-3 flowers and marked its point of departure. I followed it to the next inflorescence it alighted upon and then flicked the bee away from the flower it was about to probe. Using wicks, I measured the nectar in the 5 flowers in the ring following its point of departure from the first inflorescence, the flower at which it alighted at the second inflorescence, and the 4 flowers on either side. Since individual bees showed no preference for clockwise over anticlockwise progress around the ring, I pooled the sequences within each flower position from either side of where the bee alighted. I repeated this procedure with 12 bees on each of two days. This experiment was conducted in 1988.

Using Kruskal-Wallis tests, I compared the nectar distributions that the bees would have encountered had they continued to probe flowers at the first and second inflorescence both between corresponding flower positions and between all flowers sampled on the inflorescences. I also calculated the rates that bees would have received nectar at the 2 inflorescences using the means of the pooled flight and probe times.

\section{Experiment 1: how are bumblebees' movement decisions influenced by the distribution of nectar rewards?}

I marked out a $1 \times 1 \mathrm{~m}$ quadrat containing about 60 inflorescences of $M$. fistulosa. I manipulated the nectar in 4 groups of 6 inflorescences. These 24 inflorescences were dispersed haphazardly in the quadrat and identifiable by a numbered tag on the stem. During the experiment, bees foraged mainly on unmanipulated inflorescences so I assume that they responded to the manipulated inflorescences in accordance with their natural decision making process. After all senescent flowers were removed, the 4 treatments were as follows: all flowers on the inflorescence were emptied with wicks immediately prior to the experiment (group E); all flowers on the inflorescence were emptied 3 hours prior to the experiment and then bagged in nylon mesh to exclude insects and to allow nectar to accumulate so that flowers were 'full' at the beginning of the experiment (group F); all flowers on the inflorescence were emptied 1.5 hours prior to the experiment and then bagged so that flowers were 'half full' (group F/2); the same as group F except that half the flowers were assigned at random to be emptied immediately before the experiment to produce a mixture of $\mathrm{F}$ and $\mathrm{E}$ flowers (group F \& E). (I will refer to flowers belonging to a treatment group such as $F$ as 'type $F$ ' flowers etc.). 
Once the experiment was prepared, I waited until a free-flying bumblebee entered the quadrat (always within $15 \mathrm{~min} \cdot \mathrm{s}$ ) when I placed a large net cage over the quadrat. Apparently oblivious to the cage, the bees would make many visits to the inflorescences but would finally attempt to leave the quadrat, either visually or physically encountering the cage. Often, the bee would return to foraging directly in an apparently identical manner and so I was able to obtain further visits to my treated inflorescences by a single bee. If a bee failed to continue to forage it was released and another sought if many inflorescences remained unvisited. I recorded the number of probes made to each inflorescence. I repeated this procedure 9 times in 8 days. Since wicks leave less nectar in flowers than bumblebees and because experiments were completed within $40 \mathrm{~min} \cdot \mathrm{s}$ of creating type $\mathrm{E}$ flowers, I expect that empty flowers remained so for the duration of the trials. I measured the amount of nectar in type $F$ flowers on each occasion (many type F flowers were wicked-out in the production of group ( $F \& E$ ) inflorescences). I also set up the treatments $F$ and $F / 2$ on each of 3 further days to verify their relationship in amount of nectar. This experiment was conducted in 1987

To discover whether captivity in the cage was altering the foraging behavior of the bees in experiment 1 , I compared the frequency distributions of the numbers of flowers probed at unmanipulated inflorescences in experiment 1 to that of free-flying bees using a G-test (Sokal and Rohlf 1981).

In analyzing the number of probes made to manipulated inflorescences, I present only the data collected at previously unvisited inflorescences except for group $E$ inflorescences. For group $E, I$ included data from a second visit if only 2 or fewer flowers were visited previously because revisitation of flowers was unlikely. I compared among the frequency distributions of the number of flowers probed at each group of inflorescences using G-tests.

To further test whether the number of flowers probed at an unmanipulated inflorescence was independent of the nectar rewards at the previously visited inflorescence, I composed $2 \times 2$ contingency tables where the categories were the group of the previously visited inflorescence ( $\mathrm{F}$ or $\mathrm{E}$ ) and the number of flowers probed $(=<3$ or $>3)$ at the next consecutively visited unmanipulated inflorescence.

\section{Experiment 2: what nectar rewards precede departure from an inflorescence?}

The method for this experiment is the same as that immediately above except for the nature of the treatment groups. In the quadrat, I set up 3 treatment groups, each of 5 inflorescences. To control for the potential effects of inflorescence size, I thinned each of these inflorescences to 10 non-senescent flowers. On these inflorescences, I marked each flower with a unique color code at the base of the corolla. The treatment groups were as follows: group E as above; group (E \& F) as above except that flowers alternated EFEF etc. (group EFEF); group (E \& F) as above except that the pattern was EEFFEEFF etc. (group EEFF). I used the same procedure with the bees as above but in addition I recorded the color codes of the flowers visited. In this way I could discover the sequence of nectar rewards that preceded a bee's departure from an inflorescence. I repeated the experiment twice each day for 6 days. On 9 of the trials, immediately prior to the experiment I probed type $F$ flowers with a blunt wick that did not remove any nectar (identical with the treatment of type E flowers except for the nectar removal) since I suspected that bees might be able to distinguish recently handled type E flowers.

The data were recorded as sequences of 3 types of flower visited before departure from an inflorescence; the 3 types being $E, F$ and, on revisited inflorescences, $\mathrm{P}$ (previously probed). For analysis, I pooled sequences recorded from all bees. This experiment was conducted in 1988.

Since, on previously unvisited inflorescences, the frequencies of types $E$ and $F$ flowers were known, I used a binomial distribution $(\mathrm{k}=0.5)$ to test the null hypotheses that sequences began and ended on flower types in proportion to their frequency i.e. that landing and departure behavior were not influenced by nectar in flowers. Trials in which type F flowers had received a control manipulation were analysed separately in order to discover whether the bees were able to distinguish recently handled flowers. To discover whether bees were sensitive to my having handled a flower recently once they had landed on an inflorescence, I used a $2 \times 2$ contingency table to test whether the frequency of movement response (move to next flower in ring or skip one or more) was independent of whether type $\mathrm{F}$ flowers had been recentiy handled or not. If bees discriminate against recently handled flowers when they are always type E, then they should skip flowers more frequently than when type $F$ flowers have received a control manipulation.

To discover what information bees integrated into their movement decisions, I used $2 \times 2$ contingency tables to test whether the frequency of a response (stay or depart) to probing a type of flower was independent of the type of the previously probed flower ( $E$ or $F$ ), or of the 2 previously probed flowers (EE or $F F$ ), or of the next flower to be encountered in the ring ( $E$ or F). To discover whether bees were marking flowers that they visited, I used a $2 \times 2$ contingency table to test whether the frequency of response (stay or move) was independent of whether the last flower probed was type $\mathrm{E}$ or $\mathrm{P}$.

\section{Results}

\section{Bumblebees' behavior on unmanipulated inflorescences}

Departing from an inflorescence was a frequent component of bee foraging behavior. In 1987, free-flying bees visited on average only 3.73 flowers per inflorescence (Table 1$)$. Indeed, on $21 \%$ of accasions $(n=1137)$ the bee visited only 1 flower.

Captivity does not appear to alter bees' inflorescence departure behavior since the distribution of the number of flowers probed per unmanipulated inflorescence by the captive bees in experiment 1 is not significantly different from that of free-flying bees (G-test, $p>0.4$; Table 1). The behavior of captive bees in experiment 2

Table 1. Frequency distributions (\%) of the number of flowers probed per unmanipulated inflorescence by free-flying or caged bumblebees in 1987 and 1988

Number of flowers probed per inflorescence

\begin{tabular}{lllllllllllrrr} 
& 1 & 2 & 3 & 4 & 5 & 6 & 7 & 8 & 9 & $\geq 10$ & $\bar{x}$ & $s$ \\
\hline Free 87. & 21 & 24 & 15 & 9 & 9 & 7 & 5 & 4 & 2 & 4 & 3.7 & 2.78 & 1137 \\
Caged 87. & 18 & 23 & 16 & 12 & 10 & 7 & 4 & 3 & 3 & 5 & 3.9 & 2.95 & 396 \\
Caged 88. & 22 & 20 & 15 & 12 & 10 & 5 & 5 & 5 & 2 & 3 & 3.7 & 2.75 & 998 \\
\hline
\end{tabular}


(1988) was similar to that of the captive bees in 1987 (Table 1).

\section{Do bumblebees make efficient movements between inflorescences?}

The amounts of nectar in the 5 flowers ahead of a bee's departure point from an inflorescence are compared to the nectar in the 5 flowers ahead of where it alighted on the next inflorescence in Fig. 1.

The distribution of amounts of nectar in the discarded flowers is not significantly different from that on the next inflorescence for any given position, e.g. the amount of nectar at the first flower (position 1) on the next inflorescence is not significantly different (Kruskal-Wallis, $\mathrm{p}<0.77$ ) from the amount of nectar the bees would have obtained from the next flower had they stayed on the first inflorescence. However, a significant difference is found between the amounts of nectar in the flowers of the discarded versus next-visited inflores-

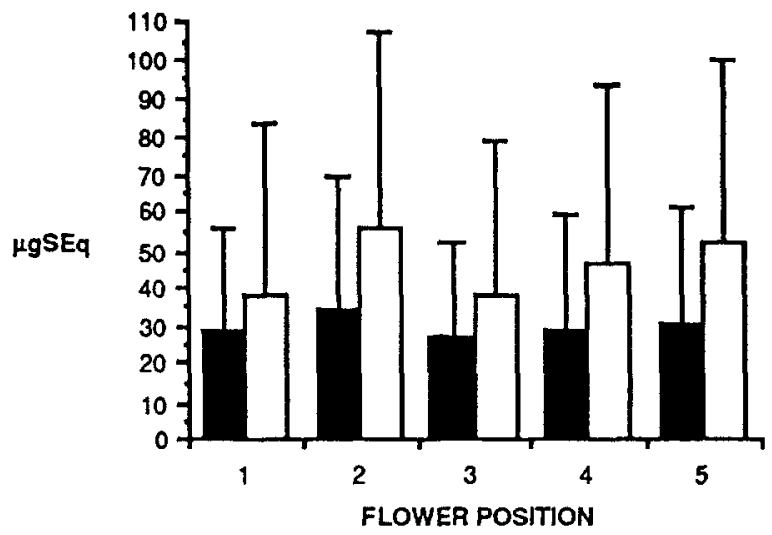

Fig. 1. The amount of nectar ( $\mu \mathrm{gSEq})$ in flowers ahead of departure point at the first inflorescence (filled bars) compared to those ahead of arrival point at the second inflorescence (open bars). Error bars show 1 standard deviation

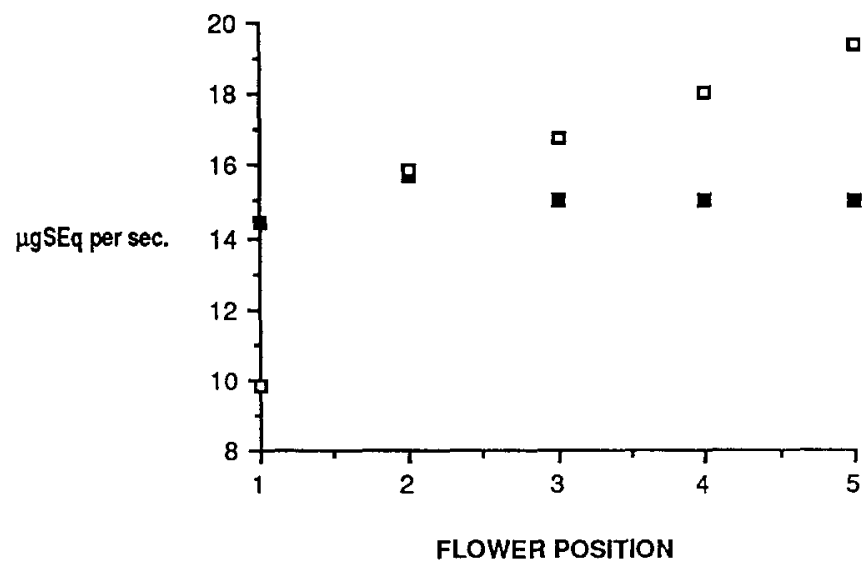

Fig. 2. The rate of nectar intake ( $\mu \mathrm{gSEq} / \mathrm{sec}$.) for an hypothetical bee foraging 1-5 flowers at an inflorescence discarded by a real bee (filled squares) or chosen by a real bee (open squares) cences when the data are pooled across all flower positions (Kruskal-Wallis, $p<0.002$ ).

The rates of nectar intake for an hypothetical bee that continued foraging on the first inflorescence and one that moved are shown in Fig. 2. The mean time taken to probe a flower including travel time to the next flower within an inflorescence was $2.0 \mathrm{~s}\left(s^{2}=0.95, n=\right.$ 907) and the mean time taken to probe a flower and fly between inflorescences was $3.82 \mathrm{~s}\left(s^{2}=1.85, n=221\right)$. The rate of nectar intake is higher for the moving bee provided it visits 2 or more flowers at the next inflorescence. Even departing as often as they do, bumblebees may be responding to inequalities in the distribution of nectar among inflorescences so as to increase the rate of nectar uptake.

Although bumblebees are making some efficient decisions, it cannot be concluded from this experiment that all bumblebee movements are efficient. Recall that the first inflorescence was always one where a bee probed only 1 or 2 flowers and bumblebees typically probe $<3$ flowers at an inflorescence on only $45 \%$ of occasions. There is no direct evidence that bumblebees are increasing profits when they probe $\geq 3$ flowers on inflorescences.
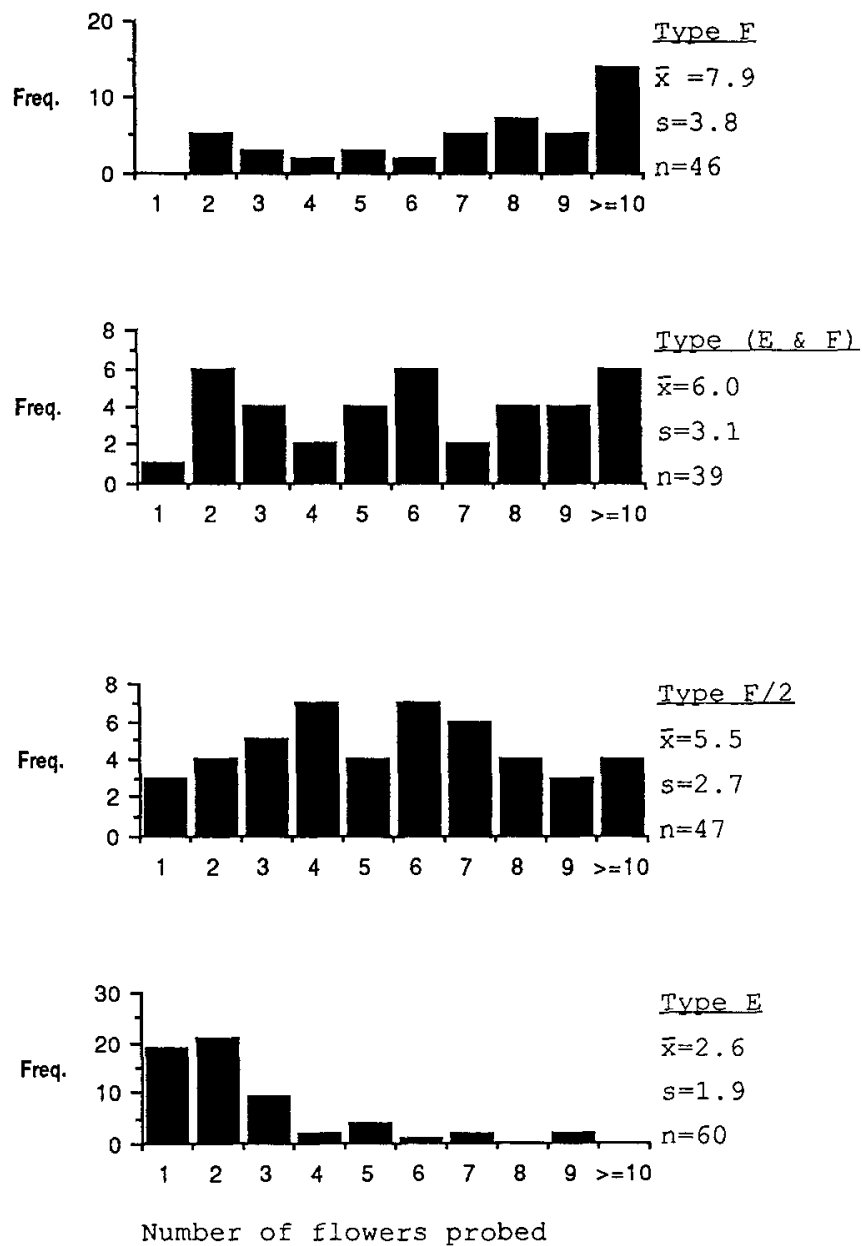

Fig. 3. Frequency distributions of the numbers of flowers probed during a single visit to manipulated inflorescences in experiment 1 
Table 2. Descriptive parameters of the nectar distribution ( $\mu \mathrm{gSEq}$ ) in the 3 inflorescence types in experiment 1 on each of 3 days. $\overline{\mathrm{x}}=$ sample mean, $s=$ sample standard deviation, $n=$ sample size

\begin{tabular}{|c|c|c|c|c|c|c|c|c|c|}
\hline & \multicolumn{3}{|c|}{ Day 1} & \multicolumn{3}{|c|}{ Day 2} & \multicolumn{3}{|c|}{ Day 3} \\
\hline & $\overline{\mathrm{x}}$ & $s$ & $n$ & $\overline{\mathrm{x}}$ & $s$ & $n$ & $\overline{\mathrm{x}}$ & $s$ & $n$ \\
\hline $\mathrm{F}$ & 149 & 79.7 & 56 & 185 & 102.6 & 48 & 219 & 120.7 & 45 \\
\hline $\mathrm{F} / 2$ & 67 & 48.5 & 48 & 124 & 68.1 & 56 & 119 & 62.8 & 43 \\
\hline$(F \& E)$ & 71 & 84.8 & 100 & 87 & 111.7 & 100 & 92 & 118.8 & 100 \\
\hline
\end{tabular}

Are bumblebees' movement decisions influenced by nectar rewards?: experiment 1

The frequency distributions of the number of flowers probed per inflorescence in the 4 treatment groups in experiment 1 are given in Fig. 3 (data are pooled from all bees). Predictably, bumblebees visited most flowers at group $\mathrm{F}$ inflorescences and least at group $\mathrm{E}$ inflorescences. Bees made an intermediate number of visits on groups $F / 2$ and $(F \& E)$, and these distributions were not significantly different (G-test, $p>0.5$ ). Therefore, inflorescences that differed in the variability of nectar in their flowers did not receive different patterns of visitation from bumblebees.

Descriptive parameters of the nectar distributions for each of the treatment groups in experiment 1 are given in Table 2. (The distribution of the ( $F \& E$ ) group is estimated as a 50:50 mixture of distributions of group F flowers and group E flowers). Although nectar production rate differed among the 3 days when the measures were taken, within each day group $\mathrm{F}$ has approximately twice the mean amount of nectar of group $F / 2$ and the variance among nectar rewards in group $(\mathrm{F} \&$ E) exceeds group F/2 by a factor of between 3 and 4 while the means are similar. While the mean nectar production rate varied among the 8 days on which experiment 1 was conducted (grand $\overline{\mathrm{x}}=204, s^{2}=45.9$ ), I assume that these qualitative relationships among treatment groups were retained.

\section{What information do bumblebees use to make their inflorescence departure decisions?}

Does the amount of nectar received at the previously visited inflorescence affect departure behavior on an inflorescence? There is no evidence that bumblebees modify their departure behavior on an inflorescence in response to the number of flowers probed at the previous inflorescence, which is an estimator of the nectar received. The number of flowers probed at an inflorescence was independent of the number probed at the previous inflorescence on all of the 9 days when data were collected from free-flying bees (the mean value of $\Sigma\left[(\mathrm{O}-\mathrm{E})^{2} /\right.$ E] was 0.58 , the maximum was $1.58, n=9 ; \chi^{2}{ }_{(1,0.05)}=$ 3.84). To test this conclusion further, I examined the number of flowers probed at unmanipulated inflorescences by captive bees in experiment 1 when the previous
Table 3. A contingency table test for the independence of the number of flowers probed an an unmanipulated inflorescence from the type (E or F) of the previous inflorescence. Expected frequency given independence in parentheses

\begin{tabular}{llr}
\hline Type of previous inflorescence & \multicolumn{2}{c}{ Number of flowers probed } \\
\cline { 3 - 3 } & $\leq 3$ & $>3$ \\
\hline E & $13(12.8)$ & $16(16.2)$ \\
F & $10(10.2)$ & $13(12.8)$ \\
& $\Sigma\left[(\mathrm{O}-\mathrm{E})^{2} / \mathrm{E}\right]=0.013$ n.s. \\
\hline
\end{tabular}

Table 4. The frequency distributions (\%) of amounts of nectar ( $\mu \mathrm{gSEq}$ ) in type $\mathrm{F}$ flowers in each of the 12 replicates. $\mathrm{n}=$ sample size, $\bar{x}=$ mean sugar per flower $(\mu \mathrm{gSEq})$. All frequencies are rounded to the nearest whole percent

\begin{tabular}{lrrrrrrrr}
\hline $\begin{array}{l}\text { Rep- } \\
\text { licate }\end{array}$ & $0-50$ & $50-100$ & $100-150$ & $150-200$ & $>200$ & $n$ & $\bar{x}$ \\
\hline 1 & 33 & 13 & 33 & 13 & 7 & 30 & 96.6 \\
2 & 40 & 40 & 14 & 6 & - & 35 & 65.1 \\
3 & 43 & 17 & 14 & 26 & - & 35 & 77.7 \\
4 & 43 & 17 & 26 & 9 & 6 & 35 & 72.9 \\
5 & 73 & 24 & - & - & 2 & 41 & 32.7 \\
6 & 40 & 26 & 26 & 6 & 3 & 35 & 70.3 \\
7 & 17 & 11 & 26 & 29 & 17 & 35 & 136.9 \\
8 & 23 & 23 & 6 & 17 & 31 & 35 & 142.4 \\
9 & 27 & 24 & 27 & 12 & 12 & 33 & 112.6 \\
10 & 62 & 6 & 18 & 9 & 6 & 34 & 56.9 \\
11 & 23 & 29 & 43 & 6 & - & 35 & 87.7 \\
12 & 40 & 3 & 9 & 3 & 37 & 35 & 130.3 \\
\hline
\end{tabular}

inflorescence was from either group $\mathrm{E}$ (empty) or $\mathrm{F}$ (full). The number of flowers probed at the unmanipulated inflorescence showed no significant dependence on the nature of the previous inflorescence $(p>0.9$; Table 3). Even when an inflorescence has been either highly rewarding or empty, the bees do not integrate that information into their movement decision at the next inflorescence.

What nectar rewards precede departure from an inflorescence?: experiment 2

In all, I recorded 92 flower visitation sequences at previously unvisited inflorescences of groups EFEF and EEFF (mean length $=3.97$ flowers, $s^{2}=2.38$ ), 70 sequences from previously visited EFEF and EEFF inflorescences $\left(\overline{\mathrm{x}}=3.26\right.$ flowers, $\left.s^{2}=2.12\right)$ and 40 sequences at unvisited group $\mathrm{E}$ inflorescences $(\overrightarrow{\mathrm{x}}=2.95$ flowers, $s^{2}=2.02$ ).

Type $\mathrm{F}$ flowers varied in their nectar content within a replicate because nectar production rates differed among flowers (Table 4). The mean amount of nectar in type $F$ flowers was relatively large compared to amounts in unmanipulated inflorescences (typically, for unmanipulated inflorescences, $20<\overline{\mathrm{x}}<60 \mu \mathrm{gSEq}$; Cresswell 1989). The mean amount of nectar in type F flowers varied among replicates (Table 4 ). 
Flower visitation sequences on previously unvisited inflorescences of groups EFEF and EEFF were significantly more likely to end with a type E (empty) flower than a type $\mathrm{F}$ flower (binomial test; $p<0.002$ ); of 92 sequences, 60 ended with a type $E$ flower. However, probing a type E flower did not invariably lead to initiation of departure. On previously unvisited group EEFF and EFEF inflorescences, only $31 \%$ of probes to type E flowers $(n=192)$ were followed by departure from the inflorescence, while on group $\mathrm{E}$ inflorescences, $34 \%$ of probes to type $\mathrm{E}$ flowers $(n=118)$ were followed by departure. Indeed, the bees demonstrated a wide range in

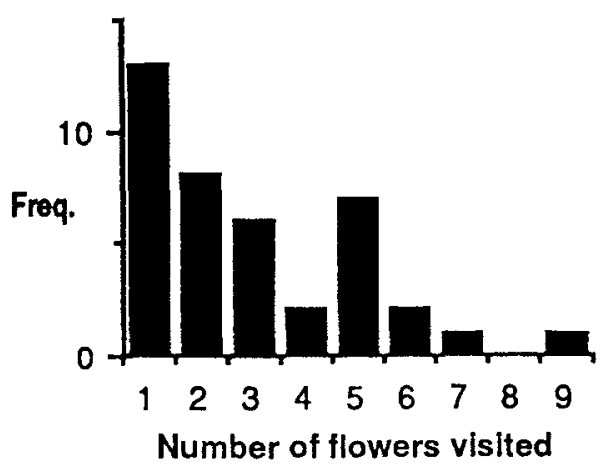

Fig. 4. The frequency distribution of the number of flowers probed at type $\mathrm{E}$ inflorescences in 1988

Table 5. The probability of departing from an inflorescence after probing a type $\mathrm{E}$ flower $[\mathrm{P}(\mathrm{D} \mid \mathrm{E})]$ for some individual bees. Bees are identified by the number of the replication they were involved in. The total number of type $E$ flowers encountered is given by n

\begin{tabular}{rll}
\hline Bee & $n$ & $\mathrm{P}(\mathrm{D} \mid \mathrm{E})$ \\
\hline 8 & 26 & 0.35 \\
11 & 17 & 0.35 \\
3 & 30 & 0.33 \\
1 & 30 & 0.33 \\
7 & 17 & 0.29 \\
5 & 26 & 0.27 \\
9 & 18 & 0.22 \\
2 & 40 & 0.18 \\
\hline
\end{tabular}

Table 6. The frequency of responses, stay or depart, of bumblebees when the first 2 flowers probed on an inflorescence were type E. Individual bumblebees are identified by the replicate they were involved in

\begin{tabular}{rll}
\hline Bee & Stay & Depart \\
\hline 1 & 1 & 2 \\
2 & 3 & 0 \\
3 & 2 & 1 \\
4 & 1 & 1 \\
5 & 3 & 0 \\
6 & 2 & 1 \\
7 & 2 & 0 \\
9 & 1 & 1 \\
10 & 1 & 1 \\
\hline
\end{tabular}

response to encountering sequences of type $\mathrm{E}$ flowers; some bees probed as many as 9 consecutive flowers at group $\mathrm{E}$ inflorescences before leaving an inflorescence (Fig. 4).

The variability in response to type E flowers occurs at the individual level; Table 5 shows the frequency with which probes to type $\mathrm{E}$ flowers preceded departure and all bees showed variability in their response to type $\mathrm{E}$ flowers. Table 6 shows the responses of some individual bees that on more than 1 occasion visited 2 or more flowers at previously unvisited group $\mathrm{E}$ inflorescences, encountering, therefore, 2 consecutive type $E$ flowers. Again, most bees showed variability in their responses.

On type $\mathrm{F}$ flowers, $17 \%$ of probes $(n=187)$ resulted in departure but the variability in response may be because type $\mathrm{F}$ flowers vary more in their nectar content.

\section{The effect on departure of previous nectar rewards at the} same inflorescence: experiment 2

The variability in responses to type $\mathrm{E}$ flowers is not explained by an effect of the type of flowers previously probed on the same inflorescence. The response by a bee (either probing further flowers or departing to another inflorescence) to probing a flower of either type

Table 7. Contingency tables testing for the independence of the frequencies of responses (stay or depart) to probing a given flower type ( $\mathrm{E}$ or $\mathrm{F}$ ) from the type of the previous flower probed ( $\mathrm{E}$ or F) for either all pairs of flowers or the first 2 flowers probed at an inflorescence. Expected frequency given independence in parentheses

\begin{tabular}{|c|c|c|c|c|}
\hline \multirow{2}{*}{$\begin{array}{l}\text { Previous } \\
\text { flower }\end{array}$} & \multicolumn{2}{|c|}{ Response to $\mathrm{E}$} & \multicolumn{2}{|c|}{ Response to F } \\
\hline & Stay & Depart & Stay & Depart \\
\hline \multicolumn{5}{|c|}{ All flowers } \\
\hline \multirow[t]{2}{*}{$\begin{array}{l}\text { Type E } \\
\text { Type F }\end{array}$} & $\begin{array}{l}31(29.6) \\
72(73.4)\end{array}$ & $\begin{array}{l}13(14.4) \\
37(35.6)\end{array}$ & $\begin{array}{l}68(65.3) \\
30(32.7)\end{array}$ & $\begin{array}{l}18(20.7) \\
13(10.3)\end{array}$ \\
\hline & \multicolumn{2}{|c|}{$\Sigma\left[(\mathrm{O}-\mathrm{E})^{2} / \mathrm{E}\right]=0.28 \mathrm{n.s}$} & \multicolumn{2}{|c|}{$\Sigma\left[(\mathrm{O}-\mathrm{E})^{2} / \mathrm{E}\right]=2.56$ n.s. } \\
\hline \multicolumn{5}{|c|}{ First 2 flowers } \\
\hline \multirow[t]{2}{*}{$\begin{array}{l}\text { Type E } \\
\text { Type F }\end{array}$} & $\begin{array}{l}31(27.9) \\
22(25.1)\end{array}$ & $\begin{array}{l}8(11.1) \\
13(9.9)\end{array}$ & $\begin{array}{l}11(11.4) \\
16(15.6)\end{array}$ & $\begin{array}{l}5(4.6) \\
6(6.4)\end{array}$ \\
\hline & \multicolumn{2}{|c|}{$\Sigma\left[(\mathrm{O}-\mathrm{E})^{2} / \mathrm{E}\right]=2.56$ n.s. } & \multicolumn{2}{|c|}{$\Sigma\left[(\mathrm{O}-\mathrm{E})^{2} / \mathrm{E}\right]=0.08$ n.s. } \\
\hline
\end{tabular}

Table 8. A contingency table testing for independence of the frequencies of the responses (stay or depart) to the $3^{\text {rd }}$ flower being type $E$ from the types of the first 2 flowers probed (EE or FF). Expected frequency given independence in parentheses. Although the test incorporates expected values $<5$, this makes acceptance of the null hypothesis a stronger result

\begin{tabular}{llc}
\hline Previous 2 flowers & \multicolumn{2}{l}{ Response to E } \\
\cline { 2 - 3 } & Stay & Depart \\
\hline EE & $6(8.1)$ & $13(10.9)$ \\
FF & $6(3.9)$ & $3(5.1)$ \\
& $\Sigma\left[(\mathrm{O}-\mathrm{E})^{2} / \mathrm{E}\right]=2.94$ n.s. \\
\hline
\end{tabular}


$\mathrm{E}$ or type $\mathrm{F}$ was not significantly dependent on the type of the previous flower probed (chi-squared test, $p>0.1$; Table 7).

Using the data from all 3 treatment groups, the response when the third flower probed at an inflorescence was type $\mathrm{E}$ was not significantly dependent on whether the first 2 flowers probed were type $E$ or either included at least 1 of type $F$ (chi-squared test, $p>0.25$ ) or were both type $F$ (chi-squared test, $p>0.08$; Table 8 ). I conclude that bumblebees do not integrate into their departure decision information from previously visited flowers at an inflorescence other than the flower they have most recently probed.

The effect on departure of the number of flowers probed at an inflorescence: experiment 2

If bumblebees keep account of how many flowers they have probed at an inflorescence, then it might be expected that this would have some effect on departure proneness. For example, bumblebees may be unlikely to depart while probing the first few flowers at an inflorescence because probing them is necessary for assessment of the inflorescence. The relative frequency of departure per flower probed at the $n^{\text {th }}$ consecutively visited flower at an inflorescence is given in Table 9.

Bumblebees have a lower relative frequency of departure on type F flowers than on type $\mathrm{E}$ flowers. Bumblebees are very unlikely to depart immediately from an inflorescence when the first flower probed is type $F$. The relative frequency of departure after probing a type E flower is insensitive to the number of flowers probed previously for the first 3 flowers probed (positions 1-3), although bumblebees are somewhat more departure prone at positions 47 .

Can bumblebees detect nectar without probing a flower?: experiment 2

Since type F flowers often contain large amounts of nectar compared to most unmanipulated flowers, it was possible that bees may have been able to detect the presence of this nectar. As shown in Table 10, bees in experiment 2 did not land significantly more often than expected by chance on type $\mathrm{F}$ flowers once I had controlled for my handling of the flowers. Bees were able to avoid type E flowers significantly more often than expected when these were the only flowers that I handled immediately prior to the experiment (binomial test, $p<0.02$; Table 10).

However, once landed on an inflorescence, whether a bee moved to the next adjacent flower or skipped at least 1 flower was not dependent on whether flowers were handled recently or not (chi-squared test, $p>0.25$; Table 11). Once landed, it appears that bees are unable to avoid empty, recently handled flowers either because
Table 9. The relative frequency of departures per flower probed for the $\mathrm{n}^{\text {th }}$ consecutively visited flower position. The table shows the frequency with which bumblebees departed from an inflorescence on encountering a flower in the $n^{\text {th }}$ position that was either a type $E$ or type $F$ flower. \# $f=$ the number of occasions a bee was seen to probe a flower in a given category. \# $d=$ the number of times the bee subsequently departed from the inflorescence. $d /$ $\mathrm{f}=$ the relative frequency of departure from a flower

\begin{tabular}{|c|c|c|c|c|c|c|}
\hline \multirow{3}{*}{$\begin{array}{l}\text { Flower position } \\
\text { n }\end{array}$} & \multicolumn{6}{|c|}{ Flower type } \\
\hline & \multicolumn{3}{|l|}{$F$} & \multicolumn{3}{|l|}{$\mathrm{E}$} \\
\hline & $\# \mathrm{f}$ & $\# \mathrm{~d}$ & $\mathrm{~d} / \mathrm{f}$ & $\# \mathrm{f}$ & $\# \mathrm{~d}$ & $\mathrm{~d} / \mathrm{f}$ \\
\hline 1 & 59 & 4 & 0.07 & 80 & 22 & 0.28 \\
\hline 2 & 38 & 12 & 0.26 & 80 & 20 & 0.25 \\
\hline 3 & 26 & 3 & 0.12 & 55 & 14 & 0.25 \\
\hline $4-7$ & 61 & 12 & 0.20 & 85 & 32 & 0.38 \\
\hline
\end{tabular}

Table 10. Frequencies of the type of flower, F or E, encountered by bees alighting on manipulated inflorescences in experiment 2 . A binomial test indicates a significant deviation from chance only when the manipulation of type $\mathrm{E}$ flowers is not controlled for

\begin{tabular}{llrl}
\hline & \multicolumn{2}{l}{ Type of flower } & \\
\cline { 2 - 3 } & $\mathrm{F}$ & $\mathrm{E}$ & \\
\hline Not controlled & 17 & 6 & $p<0.02$ \\
Controlled & 39 & 34 & n.s. \\
\hline
\end{tabular}

Table 11. A contingency table test for the independence of the frequency of moving to the next adjacent flower or skipping at least 1 flower from whether the manipulation of type $E$ flowers was controlled for. Expected frequency given independence in parentheses

\begin{tabular}{lcl}
\hline & Move to adjacent & Skip \\
\hline Not controlled & $74(71.2)$ & $22(24.8)$ \\
Controlled & $164(166.8)$ & $61(58.2)$ \\
& $\Sigma\left[(\mathrm{O}-\mathrm{E})^{2} / \mathrm{E}\right]=0.61$ n.s. & \\
\hline
\end{tabular}

Table 12. Contingency tables testing the independence of the frequencies of responses (stay or depart) to probing either a type $E$ flower or a type $F$ flower from the type of the next flower ahead. Expected frequency given independence in parentheses

\begin{tabular}{|c|c|c|c|c|}
\hline \multirow[t]{2}{*}{ Flower ahead } & \multicolumn{2}{|c|}{ Response to $\mathrm{E}$} & \multicolumn{2}{|c|}{ Response to $\mathrm{F}$} \\
\hline & Stay & Depart & Stay & Depart \\
\hline Type E & $31(33.5)$ & $13(10.5)$ & $72(73.1)$ & $37(35.9)$ \\
\hline \multirow[t]{2}{*}{ Type F } & $68(65.5)$ & $18(20.5)$ & $30(28.9)$ & $13(14.1)$ \\
\hline & \multicolumn{2}{|c|}{$\Sigma\left[(\mathrm{O}-\mathrm{E})^{2} / \mathrm{E}\right]=1.18 \mathrm{n.s}$} & $\Sigma[(\mathrm{O}-\mathrm{E})$ & $/ E]=0.18 \mathrm{n} . \mathrm{s}$ \\
\hline
\end{tabular}

they can only distinguish them while in flight or because they have entered a stereotyped movement pattern. Consequently, there is no evidence to suggest that bumblebees were responding other than to nectar rewards once 
Table 13. A contingency table test for the independence of the frequencies of responses (stay or depart) from the type of flower probed ( $E$ or type $P)$. Expected frequency given independence in parentheses

\begin{tabular}{lll}
\hline Flower type & \multicolumn{2}{c}{ Response } \\
\cline { 2 - 2 } & Stay & Depart \\
\hline $\mathrm{E}$ & $77(73.2)$ & $22(25.8)$ \\
$\mathrm{P}$ & $82(85.8)$ & $34(30.2)$ \\
\hline
\end{tabular}

they had landed on the inflorescences that I manipulated.

In experiment 2 , the bees' response to probing an empty flower was independent of the type of flower ahead of them (chi-square test, $p>0.25$; Table 12), further suggesting that bees cannot detect nectar in these flowers without probing them.

In experiment 2 , the frequency of bees staying on an inflorescence or moving to another was independent of whether they had just probed a type $\mathrm{P}$ flower or a type E flower (chi-squared test, $p>0.20$; Table 13). This suggests that bees do not detect that a flower has been recently visited by themselves.

\section{Discussion}

The decision-making process adopted by bumblebees to govern the initiation of movements between inflorescences of wild bergamot can be characterized as follows:

1. movement decisions are based on the amounts of nectar encountered in flowers; initiation of departure from an inflorescence becomes less likely with increasing nectar rewards.

2. the nectar in flowers is assessed during its removal, the nectar content of flowers is not apparent to bees otherwise.

3. a bee's response to encountering a given amount of nectar in a flower is not invariably either to depart or to stay on the inflorescence.

4. movement decisions at a given inflorescence are not influenced by the bee's behavior at the previous inflorescence.

5. movement decisions at a given flower are not influenced by the nectar encountered at the previously probed flower at the same inflorescence.

6. movement decisions at a given inflorescence are weakly influenced by the number of flowers already probed at that inflorescence.

Other studies have found that the quantity of nectar received by a bumblebee at a flower decreases the likelihood that the bee will leave the inflorescence (Waddington 1981; Pyke 1982; Zimmerman 1983; Galen and Plowright 1985; Kato 1988). However, in other cases, the movement decisions of bumblebees have been shown to have been influenced by the nectar in the previous flower at the same inflorescence (Hartling and Plowright
1978) and by the nectar in previously visited inflorescences (Thomson et al. 1982; Cibula and Zimmerman 1986). While it is possible that the bumblebee species in my study ( $B$. bimaculatus) has lesser cognitive capabilities than other bumblebees, it may be that incorporation of the previous inflorescence or flower into a foraging decision does not add any useful information (Cresswell 1989). Therefore, the amount of information influencing a decision is determined by the strength of the pattern in the nectar distribution.

While at least one study has noted variability in bumblebees' responses to similar sizes of nectar reward (Hodges 1985a), this has been attributed to 'violations' of a deterministic foraging rule, perhaps for the purpose of sampling to update a foraging strategy. Below, I argue that the variability in responses may be intrinsic to a strategy for bumblebees exploiting bergamot. Certainly, the overall decision-making process adopted by $B$. bimaculatus leads to the initiation of departures from inflorescences in such a way as to enhance foraging efficiency.

\section{Comparison with previously formulated rules}

The bees' behavior does not conform with Hodges' threshold departure rule (Hodges 1985a, b). While bees appear to base their departure decision on only the last flower probed as as the case for the threshold departure rule, the response to a particular nectar reward is not invariable; bees depart after probing empty flowers on only $\approx 30 \%$ of occasions. The variation in the response to empty flowers conflicts with Hodges' threshold departure rule since an empty flower must be a subthreshold reward otherwise bees using this rule would never leave an inflorescence.

The bees' behavior does not conform with the consistent application of one of the 'rules-of-thumb' proposed for patch assessment by sampling. The bees' behavior is not in accordance with a fixed giving-up-time rule because of the variation in the number of consecutively probed empty flowers that precede departure. The bees' behavior does not support the operation of the modified counting rule for the same reason. Furthermore, if departure is determined by the sum of previous nectar rewards at an inflorescence then the departure decision would be very likely to be dependent on nectar in previous flowers. However, departure from an inflorescence is not dependent on the nectar received at the the previous flower at an inflorescence.

Although the various rules have been discounted on the basis of qualitative evidence, there are no likely explanations for the poor concordance of the observations with the predictions of the rules. For example, perhaps the bees forage by a deterministic foraging rule but the rule is so frequently updated that the responses appear variable? However, information from the previously visited inflorescence might be expected to be the basis of an updating procedure yet the bees do not appear to integrate this into their departure decisions. Perhaps the bee is perceiving another source of information that 
qualifies its response to a given nectar reward? It is possible that distance to the next inflorescence could be taken into account by the bee, but since there are 60 inflorescences per $\mathrm{m}^{2}$, the variation in travel time could be trivial compared to the fixed time investment in takeoffs and landings. Furthermore, bees do not appear to discriminate among the sexual phases of the flowers (Cruden et al. 1984) nor are bees responding to previously visited flowers. Bees were not more departure prone after probing empty flowers that had been recently visited by bees compared to those that had not, suggesting that they did not employ scent marking (c.f. Cameron 1981; Marden 1984).

Since none of the rules discussed previously seem applicable, I propose a novel 'rule'; the probability of departure given a particular nectar reward $=k(0<k<$ 1 ), and $k$ decreases with increasing nectar reward. The rule is probably a simplification of the real process, but it accounts for much of the observed behavior. It is consistent with the observation that bees make departure decisions apparently on the basis of nectar received at a single flower and that the probability of departure is weakly sensitive to the number of flowers probed on an inflorescence. In addition, it is consistent with the observation that the bees' response to a given nectar reward is variable.

The rule that I propose has some reasonable implications. Given inequality in the distribution of nectar rewards among inflorescences, it would be profitable to become more departure-prone after encountering a small nectar reward. Although, as proposed here, the rule is static and with no learning behavior implied, yet the opportunity for learning is available. Since the forager using this rule will not respond consistently to identical situations, the relative value of different response options could be evaluated and the rule adjusted accordingly. The rule, which is a function relating size of nectar reward to probability of subsequent departure, can be adjusted through its 'tuning parameter' which is the shape of the function.

A rule with a probabilistic form has probably not been proposed before since it is clearly suboptimal where a stable prey distribution can be learnt by a predator, as in many optimality models, since then there is usually a single optimal response to any given situation. A probabalistic rule could be adaptive where the distribution of prey items is not stable; the distribution of nectar among inflorescences of wild bergamot varies in space and time (Cresswell 1989). In typical models, prey items are distributed into patches with the number of items per patch dictated by a stable probability distribution. Non-stable prey distributions have yet to be modelled since much data would be required to discover just how a resource distribution might be non-stable.

In general, a probabalistic rule may be adaptive in providing a combination of sampling and exploitation (Bovet 1985), a compromise between efficiency and the need to break rules in order to learn whether they are working. Alternatively, a probabilistic rule may be the result of neuronal circuitry that is incapable of a consis- tent response such that the variability in responses may not be adaptive. There may be a trade-off between the cost of improved circuitry and the cost of inefficient foraging (Cheverton 1982). Elsewhere, I show that a probabilistic response to nectar rewards (and to empty flowers in particular) can be a rate-maximizing strategy (Cresswell 1989) for a reason that is peculiar to radially arranged inflorescences where a systematic forager risks following around in its own track.

While it would be convenient if all bumblebees used the same foraging rule under all circumstances, it seems likely that the decision-making process adopted by bumblebees varies between systems. At present, it is not clear whether these differences are attributable to variation among species-specific foraging behaviors or whether each bumblebee species has considerable latitude to adapt its behavior to a given foraging problem. Comparative studies of more than one species foraging on the same nectar distributions could address this question.

\section{The effect of nectar distribution on bumblebees' function as pollinators}

Bumblebees' response to nectar is broadly predictable in that they visit more flowers at inflorescences with more nectar. While it is possible that the pattern of nectar production exhibited by wild bergamot has adapted to enhance pollination success by affecting bumblebee movements, influence of the variability among nectar rewards is unlikely to have been an important feature. In experiment 1 , bees visited similar numbers of flowers at inflorescences that had similar mean amounts of nectar but very different distributions in their flowers; the ratio of the variances of the nectar rewards in the 2 types of inflorescences was between 3 and 4 . Note that this experiment does not address risk-sensitivity by bumblebees. While inflorescences differed in the variability of the nectar contained in their flowers, the variability was not externally distinguishable so that the bumblebees were not able to choose among inflorescences on this basis. Consequently, in this case, the bumblebees cannot make risk-sensitive choice sensu Real and Caraco (1986). Since pollinators sometimes will not respond differently to differing distributions of nectar rewards, further empirical work is required to support speculations about adaptive nectar production strategies by plants (Pleasants 1983; Zimmerman and Pyke 1986).

Acknowledgements. This work was supported by funds from the University of Michigan Rackham School of Graduate Studies and an E.S. George Reserve research grant.

\section{References}

Bovet $\mathrm{P}$ (1985) The adaptive fitness of randomness in choice and foraging behavior. Beh Brain Sci 8:315-330

Cameron SA (1981) Chemical signals in bumblebee foraging. Beh Ecol Sociobiol 9:257-260 
Charnov EL (1976) Optimal foraging: the marginal value theorem Theor Pop Biol 9:129-136

Cheverton J (1982) Bumblebees may use a suboptimal arbitrary handedness to solve complex foraging decisions. Anim Beh 30:934-935

Cibula DA, Zimmerman M (1986) The effect of plant density on departure decisions: testing the marginal value theorem using bumblebees and Delphinium nelsonii. Oikos 43:154-158

Cowie RJ (1977) Optimal foraging in great tits (Parus major). Nature $268: 137-138$

Cresswell JE (1989) Optimal foraging theory applied to bumblebees gathering nectar from wild bergamot. Ph.D. thesis, University of Michigan, MI, USA

Cruden RW, Hermanutz L, Shuttleworth J (1984) The pollination biology and breeding system of Monarda fistulosa (Labiatae). Oecologia 64:104-110

Emlen JM (1966) The role of time and energy in food preference. Am Nat 100:611-617

Galen C, Plowright RC (1985) The effects of nectar level and flower development on pollen carry-over in inflorescences of fireweed (Epilobium angustifolium) (Onagraceae). Can $\mathbf{J}$ Bot 63:488491

Green RF (1980) Bayesian birds: a simple example of Oaten's stochastic model of optimal foraging. Theor Pop Biol 18:244 256

Hartling LK, Plowright RC (1978) Foraging by bumble bees on patches of artificial flowers: a laboratory study. Can J Zool $57: 1866-1870$

Hodges CM (1981) Optimal foraging in bumblebees: hunting by expectation. Beh Ecol Sociobiol 9:41-44

Hodges CM (1985a) Bumble bee foraging: the threshold departure rule. Ecology 66:179-187

Hodges CM (1985b) Bumble bee foraging: energetic consequences of using a threshold departure rule. Ecology 66:188-197

Iwasa I, Higashi M, Yamamura N (1981) Prey distribution as a factor determining the choice of optimal foraging strategy. Am Nat 117:710-723

Janetos AC, Cole BJ (1981) Imperfectly optimal animals. Beh Ecol Sociobiol 9:203-209

Kato M (1988) Bumblebee visits to Impatiens spp:: pattern and efficiency. Oecologia 76:364-370

Krebs JR, Ryan JC, Charnov EL (1974) Hunting by expectation or optimal foraging? A study of patch use by chickadees. Anim Behav 22:953-964

Lima SL (1984) Downy woodpecker foraging behavior: efficient sampling in simple stochastic environments. Ecology 65:166174
Lima SL (1985) Sampling behavior of starlings foraging in simple patchy environments. Beh Ecol Sociobiol 16:135-142

MacArthur RH, Pianka ER (1966) On optimal use of a patchy environment. Am Nat 100:603-609

Marden JH (1984) Remote perception of floral nectar by bumblebees. Oecologia $64: 232-240$

Maynard-Smith J (1978) Optimization theory in evolution. Ann Rev Ecol Syst 9:31-56

Mazur JE (1983) Reply to Staddon and Hinson. Science 221:977

McKenna MA, Thomson JD (1988) A technique for sampling and measuring small amounts of floral nectar. Ecology 69:13061307

McNair JN (1985) Optimal foraging for operant conditioners. Beh Brain Sci 8:343-344

McNamara J, Houston A (1980) The application of statistical decision theory to animal behavior. J Theor Biol 85:673-690

Ollason JG (1980) Learning to forage- optimally? Theor Pop Biol 18:44-56

Pleasants JD (1983) Nectar production patterns in Ipomopsis aggregata (Polemoniaceae). Am J Bot 70:1468-1475

Pyke GH (1979) Optimal foraging in bumblebees: rule of departure between flowers within inflorescences. Anim Beh 27:1167-1181

Pyke GH (1982) Foraging in bumblebees: rule of departure from an inflorescence. Can J Zool 60:417-428

Real L, Caraco T (1986) Risk and foraging in stochastic environments. Ann Rev Ecol Syst 17:371-390

Rea1 L, Rathcke BJ (1988) Patterns of individual variability in floral resources. Ecology 69:728 -735

Schoener TW (1971) Theory of feeding strategies. Ann Rev Ecol Syst 2:369-404

Sokal RR, Rohlf FJ (1981) Biometry (2nd ed.) W.H. Freeman and Co., NY, USA

Staddon JER, Hinson JM (1983) Optimization: a result or a mechanism? Science $221: 976-977$

Stephens DW, Krebs JR (1986) Foraging Theory. Princeton University Press, NJ, USA

Thomson JD, Maddison WP, Plowright RC (1982) Behavior of bumbleebee pollinators of Aralia hispida Vent. (Araliaceae). Oecologia 54:326-336

Waddington KD (1981) Factors influencing pollen flow in bumblebee-pollinated Delphiniun virescens. Oikos 37:153-159

Zimmerman M (1983) Plant reproduction and optimal foraging: experimental nectar manipulations in Delphinium nelsonii. Oikos $41: 57-63$

Zimmerman M, Pyke GH (1986) Reproduction in Polemonium: patterns and implications of floral nectar production and standing crops. Am J Bot 73:1405-1415 